\title{
LONG TEMPORAL ANALYSIS OF THE MODIS AEROSOL PRODUCT OVER HUAIHAI ECONOMIC REGION IN CHINA
}

\author{
Jing Chen, Yingjie Li*, Qingmiao Ma, Xin Li \\ School of Geography, Geomatics and Planning, Jiangsu Normal University, 101 Shanghai Road, Xuzhou, \\ Jiangsu 221116, China - chenj0829@126.com, liyingjiejsnu@yahoo.com, maqingmiaojsnu@yahoo.com, 631463484@qq.com
}

Commission III, WG III/8

KEY WORDS: AERONET, MODIS, Aerosol Optical Depth, Validation, Huaihai Economic Region, Long Temporal Analysis

\begin{abstract}
:
The Huaihai Economic Region (HER, 32.5-36.5 ${ }^{\circ} \mathrm{N}, 114-121^{\circ} \mathrm{E}$ ) with a land area of $178,000 \mathrm{~km}^{2}$, which contains 20 cities, is one of the earliest regional economic cooperative organizations in China. The huge population (100 million, about $7 \%$ of the China's population), local heavy industries, chemical enterprises and vehicle emissions have resulted in serious air pollution. In this paper, a long-term aerosol optical depth (AOD) data set from 2000 to 2018 over HER with $10 \mathrm{~km}$ spatial resolution has been produced and analyzed from the latest version of MODIS (MODerate resolution Imaging Spectroradiometer) aerosol products. Validation results show that MODIS AOD has a strong correlation relationship $(r=0.94$, slope $=0.92)$ with Aeronet Robotic Network (AERONET) over HER. The seasonal average AOD maps indicate that the high AOD values mainly occurred with a banding distribution from southeastern to northwestern HER, with AODs larger in summer and spring than in fall and winter. Temporally, the monthly average AOD has increased since 2000 and reached the highest level in 2011 (+0.02/year); then it has obviously declined from 2012 to 2018 (-0.05/year), owing to strict air pollution control implemented since 2012. In general, the annual average AOD over HER is 0.71 for the past nearly 20 years, and in 2018, the annual average AOD firstly lower than that in 2000 . The study suggests that there has been a slightly improvement in air quality over HER and long-term and sustainable efforts should be made.
\end{abstract}

\section{INTRODUCTION}

Aerosol particles, composed of suspended solid particles and liquid droplets in atmosphere, have a significant impact on air pollution, human health, radiation budget, clouds, climate change (Kampa et al. 2008; Allen et al. 2016; Kaufman et al. 2006). Groud-based observations and satellite remote sensing are two main kinds of methods now commonly used to obtain information on aerosol products, such as aerosol optical depth (AOD), an improtant parameter that describes the aerosol extinction capability. Comparing with groud-based observations, which can only acquire accurate and frequent data over discrete and fixed locations, the long-term satellites measurements can provide an effective way for better understanding of aerosol distributions from a regional and global perspective with sufficient large-scale, high-spatial resolution, and multi-channel data. However, the accuracy of satellite-based aerosol retrieval always closely related to surface reflectivity, cloud screening, radiometric calibration, and aerosol model assumption, resulting in lower accuracy compared with ground-based observations (Kaufman et al. 1997; King et al. 1999; Bilal et al. 2013). Numerous studies regard the groud-based observations as truth data to validate the observations from various satellite sensors (Wei et al. 2019; He et al. 2010; Gao et al. 2016).

Many satellite sensors are avaliable for AOD observations such as MODIS (MODerate resolution Imaging Spectroradiometer), AVHRR (Advanced Very High Resolution Radiometer), TOMS (Total Ozone Mapping Spectrometer), and MISR (Multi-angle Imaging SpectroRadiometer). Among these sensors, MODIS, a key instrument aboard on Terra (approximately 10:30 a.m. local time) and Aqua (approximately 1:30 p.m. local time) satellites, was the most often used. MODIS measures the global earth's surface every 1 to 2 days in 36 spectral bands since 2000 and generating a long aerosol climate data records, which contains $10 \mathrm{~km}$ and $3 \mathrm{~km}$ resolution AOD products. The latest released version of MODIS aerosol products is Collection 6.1 (C6.1), which is available with various improvements in both radiometric calibration and all aerosol retrieval algorithms (Bilal, et al. 2018). Many studies have evaluated C6.1 aerosol products by using ground-based data and compared them with the previous version, indicating that the C6.1 aerosol products are generally correlated well to ground-based observations, more superior in accuracy overall, and can be used quantitatively in air quality applications (Wei et al. 2019; Bilal et al. 2018; Sayer et al. 2019). Some studies also found that 3$\mathrm{km}$ AOD product, though have higher spatial resolution, generally performs slightly worse than the $10 \mathrm{~km}$ AOD products for China (He et al. 2017).

Huaihai Economic Region (HER) is one of the earliest regional economic cooperative organizations in China that combines 20 medium-sized cities from four different provinces and centers on Xuzhou. Furthermore, it is located between Yangtze River Delta and Circum-Bohai Sea Zone, two core economic zone of China, and proper covers around $178,000 \mathrm{~km}^{2}$ with a population of about 100 million. The acceleration of economic development in this region has also accompanied with serious air pollution, especially in recent years. At present, only limited studies have attempted to analyse the long temporal and spatial variation of aerosols over this region by using remote sensing data, and more studies desperately needed, which could be

\footnotetext{
* Corresponding author
} 
helpful for effective coordinated treatment of atmospheric pollution in the whole region.

A long temporal 10-km MODIS aerosol produtcts from the latest version over HER have been collected, processed, and analyzed. The main goal of this study is to test the accuracy of MODIS AOD products in HER and analyse the temporal and spatial variations.

\section{DATA AND METHODS}

\subsection{Study Area}

The domain was located in Huaihai Economic Region (HER), the heart of the east coast China, and the spatial scope is 32.5$36.5^{\circ} \mathrm{N}$ and $114-121^{\circ} \mathrm{E}$. HER consists 20 cities from four provinces: 7 from Shandong (Rizhao, Linyi, Laiwu, Taian, Zaozhuang, Jining, Heze), 5 from Jiangsu (Yancheng, Lianyungang, Huaiyin, Suqian, Xuzhou), 5 from Anhui (Huaibei, Bozhou, Suzhou, Bengbu, Fuyang), 3 from Henan (Kaifeng, Zhoukou, Shangqiu). Its climate is semi-arid and semi-humid, and the terrain of this area is dominated by plain, as well as piece of mountains with high elevation in the northeast corner. HER is experiencing rapid industrialization and urbanization, resulting in severe air pollution problem, thus offers the opportunity to test the accuracy of the MODIS aerosol product under the condition of heavy pollution.

Figure 1 shows a combined geograpical and topographic map of HER. The area marked in blue lines in Figure 1 is Xuzhou, the central city of HER, which aims at becoming the center in terms of regional economy, commercial logistics, financial service, science and education culture in HER. Xuzhou is a typical coalindustrial city in histroy, resulted in heavy air pollution, and in recent years, Xuzhou has been fully committed to the ecomonic transformation strategy of resource-exhausted cities.

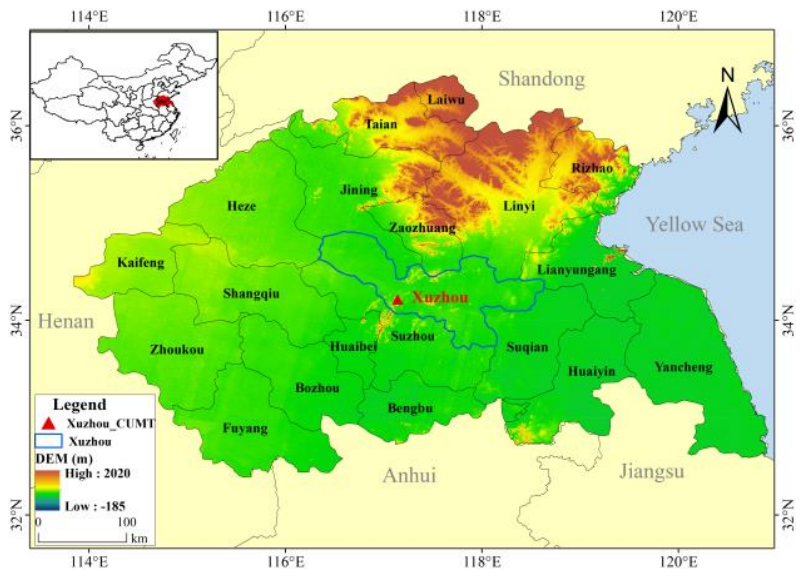

Figure 1. Study area

\subsection{Data}

The 10-km spatial resolution Terra MODIS aerosol products (Product ID: MOD04_L2) in C6.1, were collected for the period of February 2000 to December 2018. MODIS AOD product files are stored in Hierarchical Data Format (HDF-EOS), which contains many scientific datasets, here we extracted the scientific dataset named "Optical_Depth_Land_And_Ocean", which referred to aerosol optical depth at $550 \mathrm{~nm}$ with high quality assurance.

The Aeronet Robotic Network (AERONET) is a ground-based aerosol network, providing long-term and continuous AOD observations derived by Sun photometers with a low bias of approximately $0.01-0.02$. In order to validate $10-\mathrm{km}$ MOD04 AOD product, the ground-based AOD data from XuzhouCUMT site of AERONET, which is located at $34.22^{\circ} \mathrm{N}$, $117.14^{\circ} \mathrm{E}$, were downloaded from the AERONET website. Since the level 2.0 data (cloud-screened and quality-assured) are not provided, the level 1.5 data (cloud-screened) are selected. Xuzhou-CUMT is marked in red triangles in Figure 1.

\subsection{Methods}

Before conducting long temporal analysis, it is necessary to validate the AOD products with the AERONET data. Considering the spatial, temporal, and spectral differences between in situ measurements and satellite observations, some processes are essential for these datas. The in situ data averaged within 30 min of satellite overpass were extracted and compare with MODIS data averaged within $50 \mathrm{~km} \times 50 \mathrm{~km}$ window of the site. As AERONET does not make measurements at $550 \mathrm{~nm}$, data are interpolated to $550 \mathrm{~nm}$ using the equation as:

$$
\ln [\tau(\lambda)]=a_{0}+a_{1} \ln \lambda+a_{2}(\ln \lambda)^{2}
$$

where $\tau(\lambda)=\mathrm{AOD}$ at wavelength $\lambda$

$\alpha_{0}, \alpha_{1}, \alpha_{2}=$ coefficients calculated from the AERONET

AOD at $470 \mathrm{~nm}, 675 \mathrm{~nm}, 870 \mathrm{~nm}$ and $1020 \mathrm{~nm}$

After validation, monthly and seasonly AOD averages over HER are calculated and mapped by using ENVI/IDL and ArcGIS software. The four seasons are defined as spring (March, April, and May: MAM), summer (June, July, and August: JJA), fall (September, October and November: SON), and winter (December, January and February: DJF). Time series of monthly averaged AOD were polted, as well as the trend line which can clearly show the variations during the study period.

\section{RESULT AND ANALYSIS}

\section{$3.110 \mathrm{~km}$ AOD Validation}

The total validation result of $10 \mathrm{~km}$ MODIS is presented in Figure 2 and Figure 3 for seasonal validations.

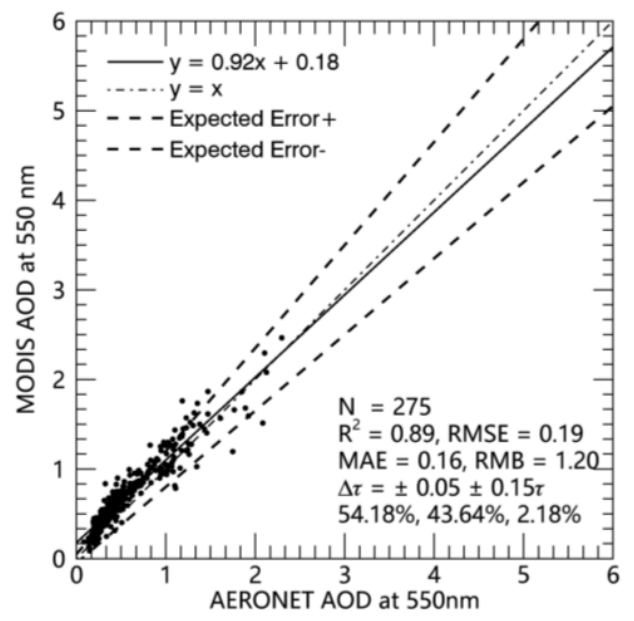

Figure 2. $10 \mathrm{~km}$ MODIS AOD validation 


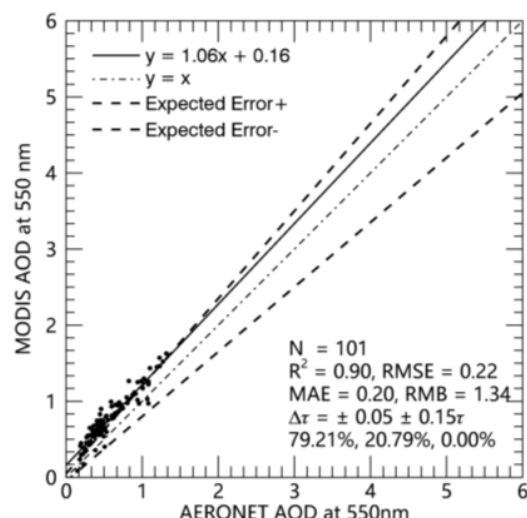

(a) Spring

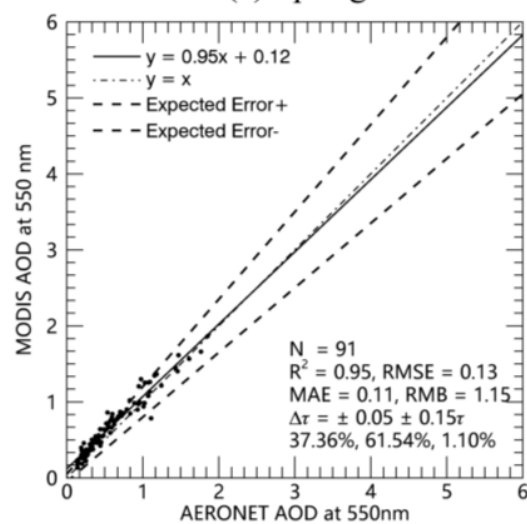

(c) Fall

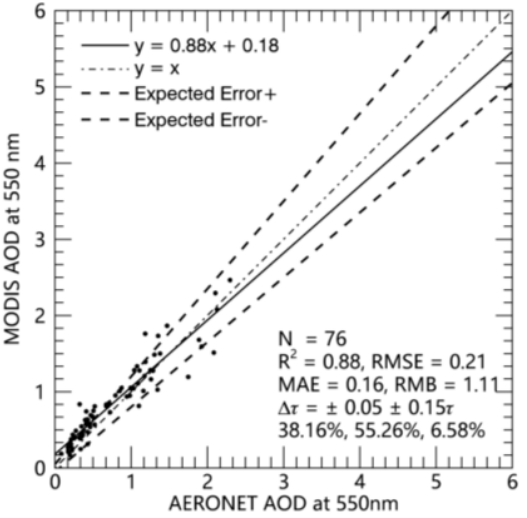

(b) Summer

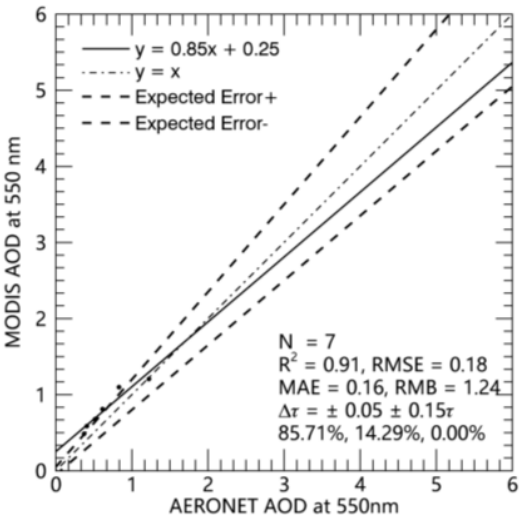

(d) Winter

Figure 3. As for Figure 2, but showing seasonal comparisons
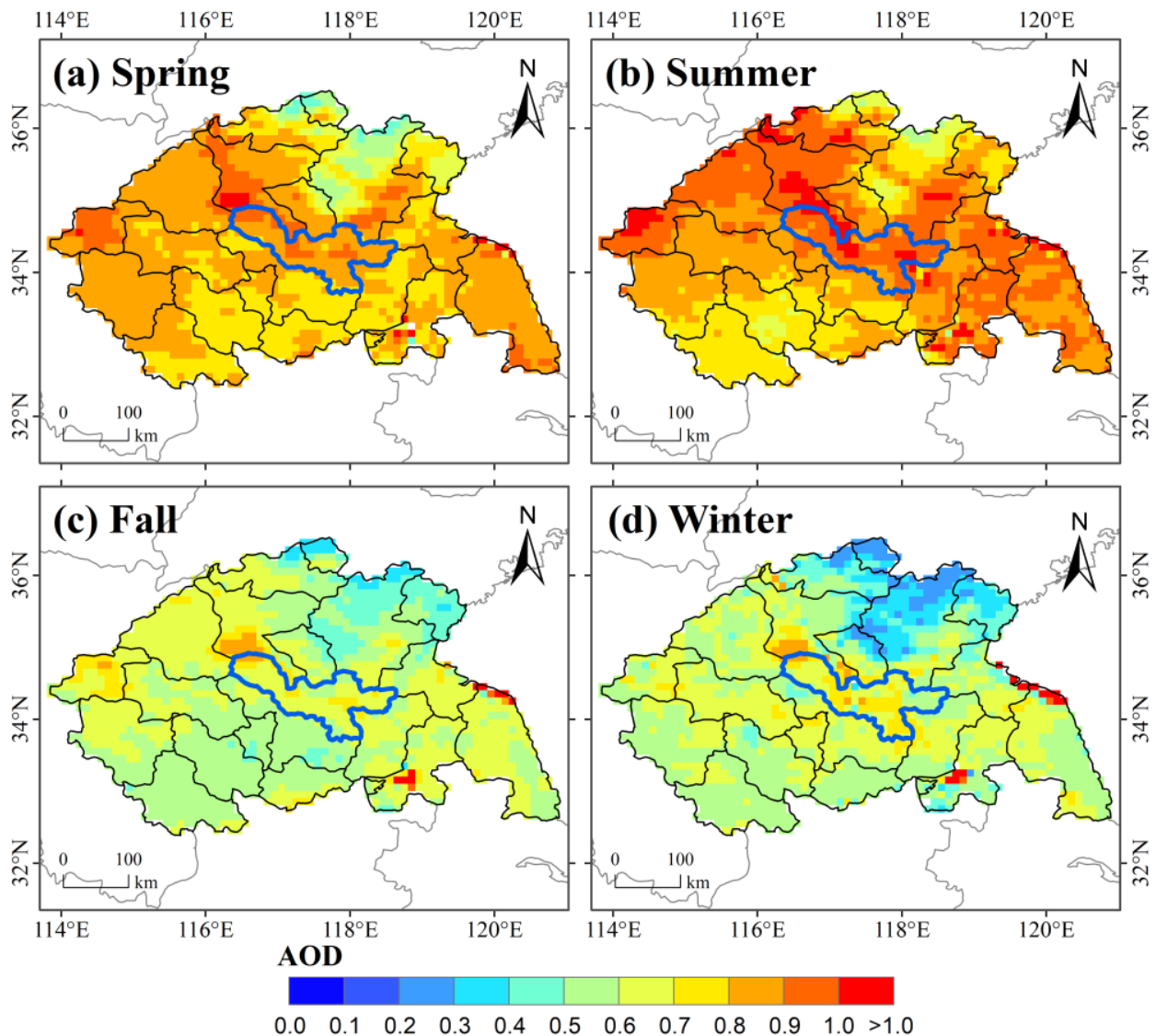

Figure 4. 2000-2018 seasonal average of $10 \mathrm{~km}$ MODIS AOD over HER 
From Figure 2, there is an obvious linear correlation between AERONET and MODIS AODs. The correlation coefficient $\mathrm{R}^{2}$ is 0.89 and the regression equation is $\mathrm{y}=0.92 \mathrm{x}+0.18$. An estinated $54.18 \%, 43.64 \%$, and $2.18 \%$ of data points lie above, within, and below the EE.

For four seasons, Figure 3 indicates that $\mathrm{R}^{2}$ varies from 0.88 to 0.95 , and the slopes of regression equations range from 0.85 to 1.06. An estimated $79.21 \%$ of data points lie aboveEE in spring, which indicates that the MODIS AOD retrievals are usually overestimated in spring. In winter, the number of data points is much smaller, because the MODIS data are often missing due to clouds, snow cover, and lack of dense vegetation.

\subsection{0 km MODIS AOD Mapping}

Seasonal AOD average over HER are calculated and charted from 10-km MODIS aerosol daily products and shown in Figure 4. Some characteristics of the aerosol spatial-temporal distribution are as follows:

1) The seasonal mean AOD loadings differ greatly in different seasons, which follow the sequence summer $>$ spring $>$ fall $>$ winter. The highest AOD of HER appears in summer and the lowest appears in winter. In summer, possibly due to the effect of higher air temperatures on the precursor of the secondary organic aerosols and photochemical interactions, which increase aerosol concentrations in the atmosphere (Liu et al. 2011), and the straw burning is also an important factor which leads to the increase in summer. In winter, for the restriction of DT algorithm, only the low AOD can be retrieved.

2) The high AOD values mainly occurred with a banding distribution from southeastern to northwestern HER, including Yancheng, Huaiyin, Xuzhou, Jining, Heze, Kaifeng, most of them are coal-industrial cities. The relatively lower AOD values occurred in the southwest and northeast. In the southwest, the population is small, and agriculture still plays an important role in these cities, which leads to less AODs for the large cover of farmland. In the northeast, many cities have always shown lower AOD values with many mountains in high elevations (see Figure 1). Some studies also find that areas with higher elevation can have lower AOD (Guo et al. 2012). In Xuzhou, the center of HER, whose AOD values almost all above 0.7 all year round, which indicates severe air pollution over there.

3) For seasonal AOD average map, some abnormal highest values are usually over coastal areas, and the inland water, which indicates that MODIS DT algorithms may have some limitations over water.

\subsection{Long Temporal Analysis}

The monthly AODs over HER from February 2000 to December 2018 are plotted in Figure 5. It shows that:

1) It is clearly that the monthly average AOD has increased since 2000 and reached the highest level in 2011, with a yearly AOD slope of +0.02 (see blue solid line in Figure 5); then it has obviously declined from 2012 to 2018, with a yearly AOD slope of -0.05 (see black solid line in Figure 5). As a whole, there is a weak downward trend (about $-0.0002 /$ year) from 2000 to 2018. The possible causes for the downward are as follows. Since 2012, the $18^{\text {th }}$ National Congress of Communist party of China has firstly proposed to build a beautiful China and pay much more attention to environmental issues. Simultaneously, cities in the research area have carried out many effectiva measures to deal with environmental problems through coopeation and have achieved some improvements.

2) In every year, the maximum AOD values always occurred in June or July, may be related to straw burning in these months, and the minimum AOD values in December or January, which are consistent with the results in Figure 4.

3) In general, the annual average AOD over HER is 0.71 for the past nearly 20 years, and in 2018, the annual average AOD is 0.54 , firstly lower than that in $2000(0.58)$.

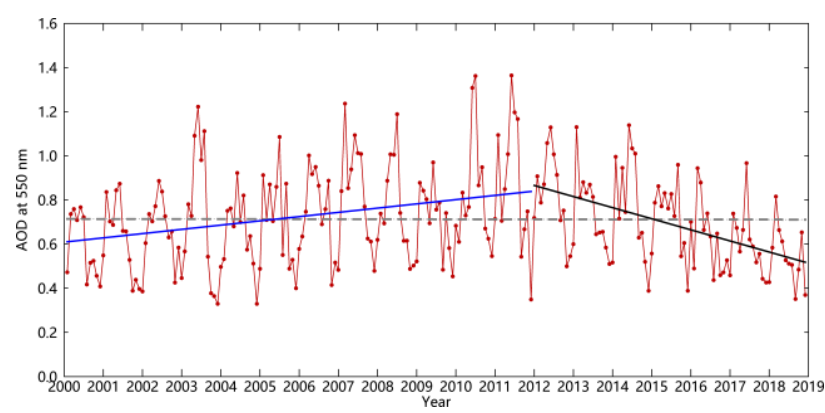

Figure 5. Time series of the averaged monthly mean AOD at $550 \mathrm{~nm}$ in HER from 2000 to 2018. The straight lines represent trend lines calculated by using linear regression analysis (blue solid line: 2000-2011, black solid line: 2012-2018, and gray dotted line: 2000-2018)

\section{CONCLUSION}

In this paper, long temporal $10 \mathrm{~km}$ MODIS aerosol product over HER were collected, processed, and analyzed. Following comparision with AERONET measurements, we calculated and mapped monthly and seasonly average AOD values, as well as the trend line slope for the study period. The following conclusions are drawing from the findings:

1) By comparing with AERONET data, MODIS AOD has a good accuracy over HER, indicating that satellite MODIS aerosol product can be an effective supplementary data for atmospheric monitoring and management.

2) The highest AOD of each year over HER usually appears in summer and the lowest usually appears in winter. Furthermore, the MODIS AOD retrievals are usually overestimated in spring.

3) The higher AOD values over HER mainly occurred with a banding distribution from southeast to northwest, most of the area were coal-industrial cities.

4) The average monthly AOD from 2000 to 2018 is 0.71 over HER, and the monthly average AOD has increased since 2000 and reached the highest level in 2011; then it has obviously declined from 2012 to 2018 mainly by the strict air control.

5) Although there is an obvious decline in AOD in recent years, the averaged AOD is still high, and to improve the air quality, long-term and sustainable efforts should be insist on.

\section{ACKNOWLEDGEMENTS}

This work was supported by the Postgraduate Research \& Practice Innovation Program of Jiangsu Province under Grant 
No. KYCX18_2155 and the Postgraduate Research \& Practice Innovation Program of Jiangsu Normal University under Grant No. 2019XKT057. The authors would like to acknowledge the MODIS team and the LAADS web for providing the MODIS aerosol products, and the Principal Investigators (PIs) and their staff for establishing and maintaining the AERONET sites used in this investigation.

\section{REFERENCES}

Allen, R. J., Landuyt, W., Rumbold, S. T., 2016. An increase in aerosol burden and radiative effects in a warmer world. Nature Climate Change, 6(3), 269-274.

Bilal, M., Nichol, J. E., Bleiweiss, M. P., Dubois, D., 2013. A simplified high resolution MODIS aerosol retrieval algorithm (SARA) for use over mixed surfaces. Remote Sensing of Environment, 136, 135-145.

Bilal, M., Nazeer, M., Qiu, Z., Ding, X., Wei, J., 2018. Global validation of MODIS C6 and C6.1 merged aerosol products over diverse vegetated surfaces. Remote Sensing, 10(3), 1-17.

Guo, Y. J., Hong, S., Feng, N., Zhuang, Y. H., Zhang, L., 2012. Spatial distributions and temporal variations of atmospheric aerosols and the affecting factors: a case study for a region in central China. International Journal of Remote Sensing, 33(12), 3672-3692.

Gao, L., Li, J., Chen, L., Zhang, L. Y., Heidinger, A. K., 2016. Retrieval and validation of atmospheric aerosol optical depth from AVHRR over China. IEEE Transactions on Geoscience and Remote Sensing, 54(11), 6280-6291.

He, Q. S., Li, C. C., Tang, X., Li, H. L., Geng, F. H., Wu, Y. L., 2010. Validation of MODIS derived aerosol optical depth over the Yangtze River Delta in China. Remote Sensing of Environment, 114(8), 1649-1661.
He, Q. Q., Zhang, M., Huang, B., Tong, X. L., 2017. MODIS 3 $\mathrm{km}$ and $10 \mathrm{~km}$ aerosol optical depth for China: evaluation and comparison. Atmospheric Environment, 153(2017), 150-162.

Kaufman, Y. J., Tanre, D., Gordon, H. R., Nakajima, T., Lenoble, J., Frouin, R., Grassl, H., Herman, B. M., King, M. D., Teillet, P. M., 1997. Passive remote sensing of tropospheric aerosol and atmospheric correction for the aerosol effect. Journal of Geophysical Research-Atmospheres, 102(D14), 16815-16830.

King, M. D., Kaufman, Y. J., Tanre, D., Nakajima, T., 1999. Remote sensing of tropospheric aerosols from space: past, present, and future. Bulletin of the American Meteorological Society, 80(11), 2229-2259.

Kaufman, Y. J., Koren, I., 2006. Smoke and pollution aerosol effect on cloud cover. Science, 313(5787), 655-658.

Kampa, M., Castanas, E., 2008. Human health effects of air pollution. Environmental Pollution, 151(2), 362-367.

Liu, X. D., Yan, L. B., Yang, P., Yin, Z. Y., North, G. R., 2011. Influence of Indian summer monsoon on aerosol loading in East Asia. Journal of Applied Meteorology and Climatology, 50(3), 523-533.

Sayer, A. M., Hsu, N. C., Lee, J., Kim, W. V., Dutcher, S. T., 2019. Validation, stability, and consistency of MODIS collection 6.1 and VIIRS version 1 deep blue aerosol data over land. Journal of Geophysical Research-Atmospheres, 124(8), 4658-4688.

Wei, J., Li, Z. Q., Peng, Y. R., Sun, L., 2019. MODIS collection 6.1 aerosol optical depth products over land and ocean: validation and comparison. Atmospheric Environment, 201, 428-440. 